\title{
A Grounded Theory Analysis of a Focus
}

\section{Group Study}

\section{Sarah Sargent}

University of Buckingham, UK

\section{Jo Samanta}

De Montfort University, UK

\section{Kudret Yelden}

Royal Hospital for Neuro-disability, UK

\section{Discipline}

Health [D4]

Sub-discipline

General Health and Social Care [SD-Hlth-1]

\section{Academic Level}

Postgraduate

\section{Contributor Biographies}


Dr. Sarah Sargent is a senior lecturer in Law at the University of Buckingham, Buckingham, UK. She has practiced law in the United States (licenses to practice currently inactive). Her research interests and publications include work in legal theory and the rights of indigenous peoples, with a focus on rights to culture and of cultural heritage.

Jo Samanta is reader in Medical Law at De Montfort University, Leicester, UK. She is a non-practicing solicitor, and she qualified as a nurse, midwife, and community health nurse in South Africa. Her research interests lie in the field of medical law and ethics, particularly in end of life decision-making. She has published widely on the interface of medical law and clinical practice.

Dr. Kudret Yelden is a consultant doctor in Rehabilitation Medicine at the Royal Hospital for Neuro-disability, London, UK. She specializes in the rehabilitation of people with severe acquired brain injuries. Her research interests and academic work lie in the area of medical law and ethics, especially human rights of people with long-term neurological conditions and end-of-life decision-making, as well as characterizing circadian rhythms and brain functions of people with prolonged disorders of consciousness.

\section{Published Articles}

Should people in the minimally conscious state have a (recognised) right to reassessment? (2016). Contemporary Issues in Law, 63-82 .

\section{Abstract}


Decisions about whether to reassess the clinical condition of patients in a minimally conscious state are a cornerstone of clinical care and management. The outcome of clinical reassessment determines whether efforts to rehabilitate should be escalated, maintained, or targeted more specifically to achieve optimal outcomes. The results of reassessment also underpin decisions to withhold or withdraw life-sustaining treatment from this patient group.

Actual decisions about whether to reassess tend to be taken by members of multidisciplinary teams. For this reason, focus groups were chosen to ascertain the views and perceptions of senior decision-makers as to whether minimally conscious patients should have a fundamental "right” to be reassessed. Constructivist grounded theory was used to analyze the data. The results reveal that a range of factors will influence whether these patients are reassessed clinically.

This case study discusses why focus groups using a grounded theory analysis were chosen to address the research question. A description is provided of the coding process that was used to develop theory from the focus group data. This case study will help researchers to understand how these methodologies are carried out as well as to identify the types of insight that can be gained from their use.

\section{Learning Outcomes}

By the end of this case study, students should be able to

- Understand how to plan for, and set up, focus group-based empirical research

- Recognize when grounded theory is an appropriate methodology to use

- Construct a plan for pursuing grounded theory analysis 
- Determine when it is useful to conduct focus groups

\section{Case Study}

\section{A Research Project Based on Focus Groups and Grounded Theory}

\section{Context}

Non-fatal severe brain injuries can lead to profound disturbances in consciousness. These potentially catastrophic injuries are most often caused by trauma, stroke, lack of oxygen, or cerebral inflammation. Following the acute insult, patients often remain in a coma for some time following which they may progress into a state called "disorder of consciousness.” This includes vegetative and minimally conscious states (MCS). Patients with MCS may remain stable but may also emerge from their current state to a higher level of conscious awareness or vice versa. In clinical practice, it can be difficult to determine whether patients are vegetative, or minimally conscious, unless regular clinical review takes place. This is important because patients who are minimally conscious might benefit from focused efforts to rehabilitate.

Care of MCS patients takes place in a range of environments. At first, care is likely to be provided in the acute sector (such as hospital emergency or intensive care departments), where the focus will be on stabilization and saving life. Transfer might then be made to a neurological rehabilitation unit where treatments such as medical care, physiotherapy, occupational therapy, and speech therapy will be provided for a period of 
time. In these units, an initial diagnosis of vegetative or MCS will be made followed by transfer to community care, such as specialist or general nursing homes. Alternatively, some patients return home to the family. Patients may live many years in their long-term care environment, and regular reassessment is recommended by current best practice guidelines.

\section{The Legal Framework}

On rare occasions, people in MCS may be able to make simple choices for daily activities such as choosing which music to listen to or what to wear. However, this ability is usually very limited, fluctuating, and inconsistent. People, who are minimally conscious, lack capacity to make even the most basic medical care decisions for themselves. In these circumstances, there are universal ethical and often legal requirements that decisions are made in the patient's best interests.

Accurate diagnosis and evaluation of MCS patients is the basis of their clinical care and management. The outcome of assessments and reassessments determine whether efforts to rehabilitate are intensified, maintained, or targeted more specifically to achieve optimal clinical outcomes. Ultimately, assessment results also underpin decisions about whether to withhold or withdraw life-sustaining treatment from MCS patients. In England and Wales, where our study took place, decisions to withdraw life-sustaining treatment from people in an MCS must also be approved by the Court of Protection.

\section{The Aim of the Study}


The aim of our study was to explore the views and opinions of senior decision-makers as to whether people in an MCS should have a right to clinical re-evaluation of their condition. Although these decisions are essentially a medical call, in a publicly funded healthcare environment whether reassessment actually happens is influenced by the wider clinical team (as well as commissioners and managers). Legal representatives might also be involved particularly if withdrawal of treatment is being considered. For this reason, our participants were drawn from all professional groups that might be involved in these decisions. They were all senior decision-makers in their fields and included intensivists, physicians, neurorehabilitation consultants, primary care physicians, anesthetists, senior nurses, occupational therapists, neuro-physiotherapists, speech therapists, lawyers, and commissioners. Inclusion of former patients was not possible as people who emerge from prolonged disorders of consciousness often have severe cognitive, communicative, and physical disability and compromised decision-making capacity. Moreover, they often have no memory of the events that took place while their consciousness was compromised.

\section{Data Collection: Focus Groups}

At an early stage in the research design, we made fundamental decisions regarding the optimal approach. All three of us are experienced in a range of research methods and approaches to data collection and analysis. We chose a qualitative approach because we felt that this would generate deep-rich data and provide optimal opportunities for in-depth exploration of the central issue. 
We also considered other data collection techniques such as semi-structured and "elite” interviews, particularly because of the seniority of our intended participants.

However, given that decisions whether to reassess patients in MCS tend to be collective, we felt that focus groups were the optimal vehicle to explore individual and group norms and attitudes. Focus groups facilitate myriad exploration of participants' views and opinions and are particularly useful for obtaining several perspectives about the same topic. Interaction between group members also encourages participants to question one another and stimulate re-evaluation of personal understandings and experiences. Focus groups also produce data based on insights that Wendy Duggleby (2005) believes cannot be accessed easily using approaches. Furthermore, focus groups, if these are the method of choice, can generate large amounts of data from several participants in a relatively short time frame.

\section{Grounded Theory Application}

A decision to use grounded theory is one that should be made after clearly ascertaining the aims of a research study. Grounded theory refers to an analytical method whereby a theory is generated from studying the data using a series of inductive examinations. This theory should then provide an answer to, or explanation of, the research issue.

This process of theory generation is different from what many researchers may be familiar with when thinking about research design. Deductive research, or hypothesis testing, is a more mainstream view of how research is done. However, using inductive methods to analyze qualitative data facilitates the expansion of knowledge. If this is compatible with the research aim, then grounded theory should be considered. 


\section{Pilot Study}

Several preliminary steps are needed prior to commencement of a research project. First, ethical approval as well as any local risk assessment or other policy requirements must be obtained. For our study, ethical approval was granted from De Montfort University, Leicester. Second, a pilot study is invaluable as a "dummy-run” to ascertain whether the method and data analysis actually works in practice, and whether it is likely to generate an answer to the research question. For this project, the pilot study was invaluable, leading us to make several practical adjustments. For example, during focus groups, particularly when conversations become animated, there was a tendency for people to speak over one another which made subsequent transcription difficult. To address this, individual audio-recorders were placed in front of each participant to more accurately collect their contributions.

\section{Conducting Focus Groups}

We held four focus groups of 2-hr duration each (29 participants in total). The groups were mixed in terms of their professional backgrounds. Participants who were known to one another and close working colleagues were allocated to separate groups in order to discourage pre-established consensus views. The groups comprised between 5 and 11 participants. Six participants per group were found to be ideal: large enough to encourage participation yet small enough to be inclusive and facilitate recording. Restricting the size of groups also prevents "splinter group” formation which happened to some degree with our larger groups. 
According to Richard Krueger and Mary Anne Casey (2008), the prevailing rule of thumb for focus groups is that homogeneous groups (e.g., separate groups of doctors, commissioners, and lawyers) tend to stimulate discussion and promote sharing of views. However, we decided against this approach. Instead, all participants were homogeneous in respect of key attributes (rather than professional status): they were all senior decisionmakers in their fields, and they were all familiar and experienced with reassessment decisions for patients in MCS. Rather than trying to achieve a unified consensus, the primary rationale was for participants to challenge one another's professional and personal perspectives to encourage exploration of possibly covert, but nevertheless basic assumptions that underpinned their beliefs about whether these patients should have a right to be reassessed.

Lynne Connelly (2015) recommends running between three and five focus groups. Having two groups only can be problematic because one group may be idiosyncratic, and it might be difficult to identify the unusual from the norm. For our study, we held four groups due to resource constraints. We also felt that theoretical sufficiency had been reached by the fourth group since by this stage no salient new views on the topic were being identified. All focus groups were held in the same venue and moderated by the same facilitator (Jo) and assisted by the clinical expert (Kudret).

The focus groups were digitally recorded. Although participants were advised to talk in turn (to facilitate transcription), Jo was often reluctant to intervene because this might have impeded conversation. Since this possibility had been identified during the pilot, several voice recorders were used so that the transcriber had several recordings to 
consult. This also meant that data from softly spoken participants could be captured more easily.

\section{Which Version of Grounded Theory to Use?}

Grounded theory is a process of coding, or interpreting, data through a series of steps. There are generally three steps to the coding process: open or initial coding, axial or focused coding, and theoretical coding, which for this study was done through the development of relational statements. After these steps are complete, an emergent interpretation or explanation of the data should become apparent. You might need to write several drafts to achieve this explanation of the "theory" which is created from the research undertaken, that is, that of a theory developed from the data, which is therefore “grounded” within it.

Our research made use of constructivist grounded theory, based on the work of Kathy Charmaz (2006) which aligns with the strand of grounded theory that was first developed by Ansel Strauss. This view is one that is beneficial to an "interpretive rendering of the worlds we study rather than an external reporting of events and statements” (Charmaz, 2006, p. 184, emphasis in original). For this study, the constructivist approach yielded important insights into the ways in which reassessment decisions were made and under what conditions: both of these were critical components.

A key feature of grounded theory is the "constant comparative" method. This means that data analysis begins as soon as it has been collected. So, immediately following each focus group, we typed transcripts and then analyzed them using a process 
of initial and axial coding. This is an important component of grounded theory methodology and analysis. Consideration of what the data means ought to begin immediately and should not wait until, for instance, all data collection has concluded. This is because the emerging analysis is relevant for setting up subsequent focus groups (Charmaz, 2006).

\section{Open/Initial Coding}

This is the first step in coding. It is important that researchers do not try to make codes fit a pre-determined idea, or goal, of what the data might reveal or how the research question should be answered. This is called "forcing the data" and is considered to be a cardinal sin in grounded theory analysis. Rather, try to code with an open mind, letting the data reveal themselves, rather than trying to presuppose what the outcome will be. It is also important to avoid reading your own personal life experiences into the data (Charmaz, 2006).

If you are already familiar with the subject area, you might well be tempted to forecast the final outcome. But one of the great strengths of grounded theory is that it can reveal hidden meanings and processes. For this reason, don't be surprised if new ideas appear through coding, particularly if these new insights are at odds with your previous perceptions about the subject matter.

Open coding is achieved through consideration of data (transcript data from each focus group) to identify initial codes. The transcripts were voluminous (a great deal can be said during $2 \mathrm{hr}$ of discussion!). There is certainly no need to look for a fixed or set number of codes in each transcript, and it is a mistake to try and do so. 
The following is an extract from our list of initial codes (pervasive themes) that emerged from the transcripts from our research. This list is provided to show you what initial codes can look like, but these are not a prescriptive template on what initial codes are, and these will vary according to the raw data from the research:

- Reassessment decisions

- Decision-making process

- Importance of knowledge and training

- Knowledge across medical fields

- Scheduling assessment

- Triggering reassessment

- Kinds of assessment

- Cost

- Patient condition

- Treatment decisions

- Source of funds

- Diagnosis

- Time span for reassessment

\section{Focused/Axial Coding}

This is the second phase of coding which builds upon the initial phase. There is no single way which axial coding can be done. What is important is for you to make informed choices when planning your grounded theory analysis. Please read about the different approaches to axial coding and decide on the one which best suits your research aims. 
Anselm Strauss and Juliet Corbin (1998, p. 127) explain the aims of axial coding:

When analysts code axially, they look for answers to questions such as why or how come, where, when, how and with what results and in so doing they uncover relationships among categories ... Why would one want to relate structure with process? Because structure or conditions set the stage, that is, create the circumstances in which problems, issues, happenings or events pertaining to a phenomenon are situated or arise. Process, on the other hand, denotes the action/interaction over time of persons, organizations, and communities in response to certain problems and issues. Combining structure with process helps analysts to get at the complexity that is so much a part of life ... Axial coding is a process that looks for relationships between the codes that were identified during initial coding. It is a step further in abstracting and analyzing data. It is important to realize, however, that axial coding is not done using the focus group transcripts. Instead, it makes use of the initial coding categories.

Our axial coding chart thus captures the essence of the description of the relationship between process and structure highlighted by Strauss and Corbin. Our research made use of an axial coding chart based in part by one developed by Wilson Scott (2004) and on the information detailed in Corbin and Strauss (1998) about the process of axial coding. The axial coding chart used in our research was used by Sarah in her unpublished PhD thesis (Sargent, 2009). 
An example of an axial coding chart with categories is shown in Table 1. This chart provides an extract of the coding done at this stage, drawn from our list of initial codes. It shows how the initial codes are further analyzed into categories and lists two of the categories that were derived from the initial coding list. Once the categories are chosen, the analysis headings that comprise "Structure/Condition" and "Process—what happened as a result of the interaction—Consequence" are considered. The "Condition” hearings are why, where, how come, and when. The "Consequence" headings are whom and how. Answering the queries about the category when considering these headings then leads to the answers that have been completed for each one. These in turn are considered when determining condition and consequence. This coding should be done where the researcher is free of distractions and has a block of time available to think about and reflect on the coding and categories. 
Table 1.

Caption: Focus group axial coding.

\begin{tabular}{|c|c|c|c|c|c|c|c|c|c|}
\hline Category & Why & Where & $\begin{array}{l}\text { How } \\
\text { come }\end{array}$ & When & $\begin{array}{l}=\text { Structure } \\
\text { condition }\end{array}$ & Whom & How & Action/interaction & $\begin{array}{l}\text { =Process } \\
\text { (what } \\
\text { happened as } \\
\text { a result of } \\
\text { interaction } \\
\text { =consequence }\end{array}$ \\
\hline $\begin{array}{l}\text { 1. Who pays } \\
\text { the cost of } \\
\text { reassessment }\end{array}$ & $\begin{array}{l}\text { Expensive } \\
\text { test, multiple } \\
\text { funding } \\
\text { sources } \\
\text { Not all } \\
\text { reassessment } \\
\text { expensive } \\
\text { (but skills }\end{array}$ & $\begin{array}{l}\text { In hospital or } \\
\text { medical } \\
\text { treatment center } \\
\text { Hospital/nursing } \\
\text { home/community }\end{array}$ & $\begin{array}{l}\text { Test } \\
\text { cannot be } \\
\text { done } \\
\text { without } \\
\text { funding }\end{array}$ & $\begin{array}{l}\text { Lack of clarity } \\
\text { annually/biannually/as } \\
\text { required when } \\
\text { changes in patient’s } \\
\text { condition noticed }\end{array}$ & $\begin{array}{l}\text { There is no } \\
\text { central place } \\
\text { to go for } \\
\text { information, } \\
\text { guidance or } \\
\text { authority on } \\
\text { any aspect of } \\
\text { reassessment, }\end{array}$ & $\begin{array}{l}\text { Family and medical } \\
\text { treatment team, lack of } \\
\text { clarity on roles } \\
\text { Lack of clarity: National } \\
\text { health service } \\
\text { (NHS)/Social care/clinical } \\
\text { commissioning groups }\end{array}$ & $\begin{array}{l}\text { Treatment } \\
\text { decisions, } \\
\text { lack of clarity } \\
\text { on } \\
\text { researching } \\
\text { funds } \\
\text { Unclear- } \\
\text { depends on }\end{array}$ & $\begin{array}{l}\text { This is highly } \\
\text { dependent on the } \\
\text { knowledge of } \\
\text { members of } \\
\text { treatment team and } \\
\text { of family } \\
\text { members. } \\
\text { Reassessment is }\end{array}$ & $\begin{array}{l}\text { Accessing } \\
\text { reassessment } \\
\text { is very "hit } \\
\text { and miss" } \\
\text { depending on } \\
\text { the location of } \\
\text { patient, } \\
\text { composition }\end{array}$ \\
\hline
\end{tabular}




\begin{tabular}{|c|c|c|c|c|c|c|c|c|c|}
\hline & required) & & & & $\begin{array}{l}\text { which cannot } \\
\text { occur } \\
\text { without } \\
\text { funds }\end{array}$ & (CCGs) & $\begin{array}{l}\text { luck/location } \\
\text { more than } \\
\text { clinical } \\
\text { circumstances }\end{array}$ & $\begin{array}{l}\text { not presented as a } \\
\text { routinized option. } \\
\text { Accessing } \\
\text { reassessment is }\end{array}$ & $\begin{array}{l}\text { of treatment } \\
\text { team and their } \\
\text { knowledge as } \\
\text { to } \sqrt{\text { Commente }}\end{array}$ \\
\hline & & & & & & & or need & $\begin{array}{l}\text { very "hit and } \\
\text { miss." }\end{array}$ & $\begin{array}{l}\text { is an option } \\
\text { and what } \\
\text { access there is } \\
\text { to funding }\end{array}$ \\
\hline $\begin{array}{l}\text { 2. When } \\
\text { assessment } \\
\text { and } \\
\text { reassessment } \\
\text { should be } \\
\text { done }\end{array}$ & $\begin{array}{l}\text { Importance } \\
\text { of test } \\
\text { results, } \\
\text { future } \\
\text { treatment } \\
\text { decisions, } \\
\text { questions on } \\
\text { optimal time } \\
\text { frames } \\
\text { agreed. Also }\end{array}$ & $\begin{array}{l}\text { Hospital or } \\
\text { treatment center } \\
\text { Hospital/nursing } \\
\text { home/community }\end{array}$ & $\begin{array}{l}\text { Relevance } \\
\text { to future } \\
\text { treatment } \\
\text { decisions }\end{array}$ & $\begin{array}{l}\text { Lack of clarity when } \\
\text { this should be brought } \\
\text { up } \\
\text { No specific rules. } \\
\text { annually/biannually/as } \\
\text { required when } \\
\text { changes in patient's } \\
\text { condition noticed }\end{array}$ & $\begin{array}{l}\text { This is an } \\
\text { important } \\
\text { decision that } \\
\text { affects the } \\
\text { patient's } \\
\text { future, which } \\
\text { is being } \\
\text { made without } \\
\text { evidence- } \\
\text { based }\end{array}$ & $\begin{array}{l}\text { Family and medical } \\
\text { treatment team } \\
\text { Doctors/nurses/family } \\
\text { members/domestics/people } \\
\text { who are likely to notice } \\
\text { change in patient's } \\
\text { condition }\end{array}$ & $\begin{array}{l}\text { Lack of } \\
\text { clarity on this } \\
\text { element } \\
\text { Yes_a range } \\
\text { of ways }\end{array}$ & $\begin{array}{l}\text { The question of } \\
\text { RA being raised is } \\
\text { dependent upon } \\
\text { observation of } \\
\text { change by } \\
\text { anyone-could be } \\
\text { family member or } \\
\text { treatment team } \\
\text { member. There is } \\
\text { no definitive }\end{array}$ & $\begin{array}{l}\text { As with } \\
\text { category 1- } \\
\text { this is all very } \\
\text { hit and miss, } \\
\text { based on those } \\
\text { same elements }\end{array}$ \\
\hline
\end{tabular}




\begin{tabular}{|c|c|c|c|c|}
\hline & $\begin{array}{l}\text { that initial } \\
\text { assessment } \\
\text { required (as } \\
\text { baseline) to } \\
\text { make } \\
\text { reassessment } \\
\text { meaningful. } \\
\text { Audit and } \\
\text { research }\end{array}$ & guidance & \begin{tabular}{|l} 
protocol or criteria \\
for decision- \\
taking, no defined \\
trigger
\end{tabular} & \\
\hline 3. & & & & $\begin{array}{l}\text { Question } \\
\text { mark—Range } \\
\text { of decisions } \\
\text { that can be } \\
\text { taken for a } \\
\text { vulnerable } \\
\text { patient, in a } \\
\text { milieu that } \\
\text { lacks clinical }\end{array}$ \\
\hline
\end{tabular}




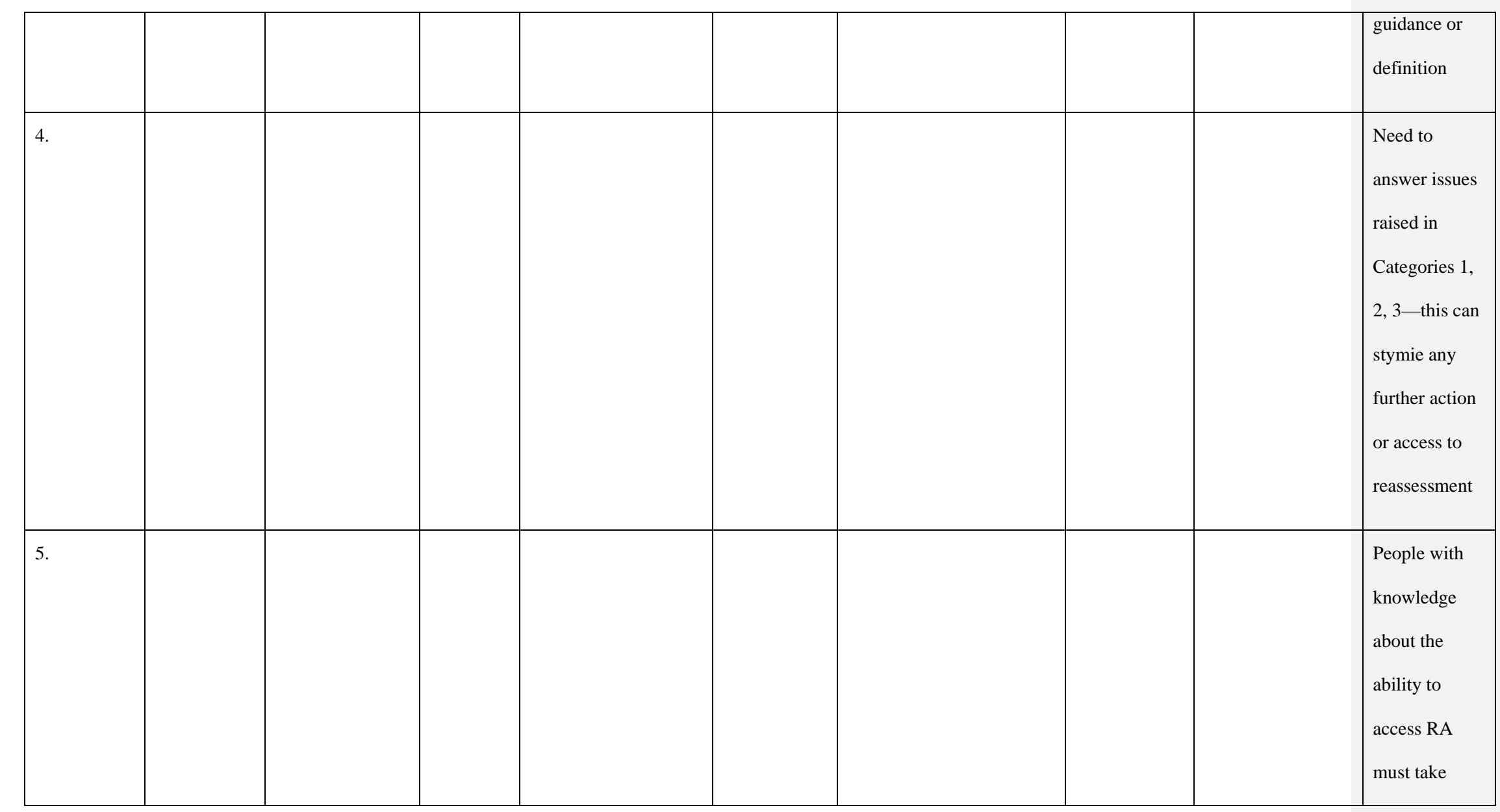




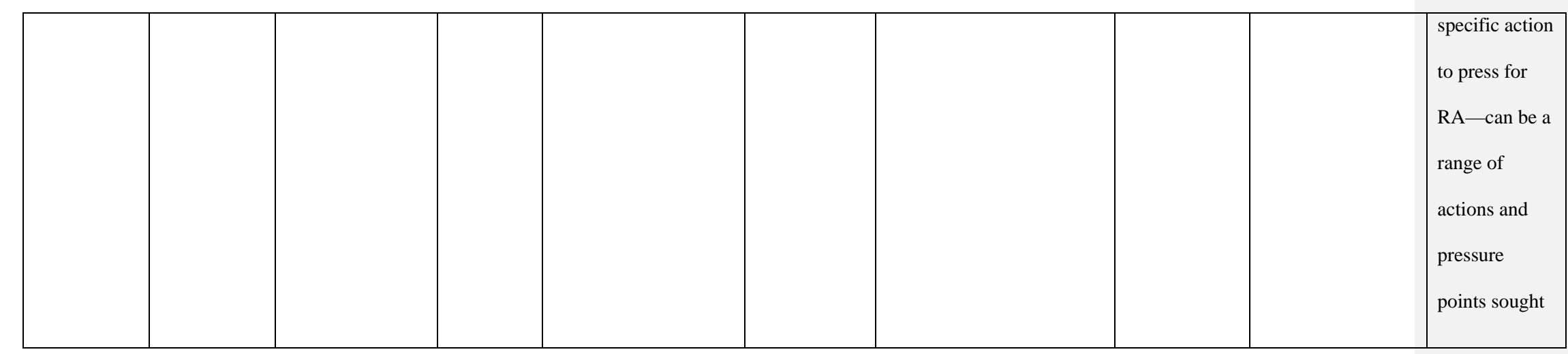




\section{Theoretical Coding/Relational Statements}

Developing relational statements is the third level of coding (this is sometimes called theoretical coding). It is at this stage that an emergent theory should become apparent, which can be a very exciting moment in grounded theory work. This stage is based on the results of the second stage of coding. Relational statements provide an effective way of crafting a narrative that helps to reveal the emergent theory.

Our relational statements were developed from the axial coding charts from each focus group (see following example). You can see how the narrative story line is drawn from the axial coding chart. This narrative becomes embedded as part of the emergent grounded theory.

\section{[TS: Box starts here.]}

Relational statements: Is there a "right" to reassessment?

There is a "hit and miss" approach to the decision to reassess a patient. There is no clear "right" to reassessment. Furthermore, there is a lack of a clear evidence base on which to proceed in making decisions. Thus, decisions become based on the presence of factors such as where the patient currently is, the composition and knowledge of the treatment team, and whether there are family or friends advocating for further assessment of the patient. These triggers are what might lead to a decision to reassess. However, reassessment is only one of a range of options that might occur when further consideration is made of the patient's condition and prognosis. Other outcomes might be to do nothing or to withdraw all treatment resulting in the death of the patient.

[TS: Box ends here.]

Final Stages: Theory Development, Theoretical Sampling, and Theoretical Saturation 
So when is a grounded theory analysis complete? Completion of coding does not signal the end of the analysis. A theory must be developed, and this may take several drafts to arrive at a finished version. However, by using the constant comparative method, development of the theory should progress as soon as there are data to analyze. To determine whether more data are needed, categories are needed and further coding undertaken, different processes can be used. For our study, we used theoretical sufficiency, which, according to some tenets, is the preferred method for determining whether adequate data analyzing has been done (Charmaz, 2006; Sargent, 2009).

\section{“Method" in Action}

\section{Research Practicalities}

Moderating focus groups can be tiring, and there is a natural tendency to want to "join the discussion.” This should be resisted to avoid influencing the data. To some extent, potential problems can be avoided at the project design stage. Ideally, the same moderator should be used. This is because the moderator's behavior and style has consequences for the character of the focus group. However, the potential for researchers to influence participants is not limited to focus groups and is common to interviews and surveys.

It is possible, at times, to experience "difficult” participants. This should perhaps be expected, particularly when moderating an "expert” group. If a participant tries to dominate the conversation, try to manage this using body language: first, by avoiding eye contact with the person and then by encouraging others' views. More direct intervention 
might be required such as "Thank you for those useful views, now I'd like to hear what XXX has to say.” More rarely a participant might challenge the moderator in some way. Although one could remind the participant politely that they are free to leave if they wish this might not be optimal. After all, that participant might have useful contributions to bring to the table. Often a calm and assertive manner works well: after all, your participants might not be accustomed to being focus group participants!

\section{Grounded Theory That Emerged From This Research Project}

For this project, Sarah and Jo coded, at first independently, and then by sharing information when constructing axial coding charts. They maintained email, telephone, and in-person contact as required throughout the coding process. Once axial coding was complete for all four focus groups, the three of us met to discuss relational statement development.

We discussed the axial coding charts, any interpretative questions, and what relational statements could be developed. Sarah took notes and assumed primary responsibility for creating the relational statements, which were then shared and used to develop the grounded theory.

\section{Writing a Grounded Theory}

Writing the grounded theory is the final step of the coding process and is unlikely to be written in a single sitting! Yet, even at this stage, the job of interpretation and analysis is not complete. Writing the grounded theory itself may also yield new insights. It is 
therefore critical not to rush this stage but to remain aware of any new understandings and links that might be evident.

\section{Practical Lessons Learned}

Qualitative research can be complex and time-consuming. It can also be incredibly rewarding and lead to new insights and policy change. Grounded theory, in particular, can produce insights that stretch far beyond the obvious and supersede what might be obtained using other methods of data analysis (such as content analysis). Even though grounded theory is based on inductive reasoning and researcher insight, remember to keep a careful paper trail of the research path so that your work can be audited.

Researchers who are interested in using grounded theory are encouraged to read a range of studies that have used this method to better appreciate its use in action and to gain an understanding of those seemingly vague and fuzzy concepts and labels.

\section{Conclusion}

Grounded theory can be a useful methodology for analyzing focus group data. Focus groups in themselves are a source of data for analysis, and one that researchers should consider, in addition to the perhaps more common place considerations of interviews or questionnaires.

What emerged from our focus group research was that there is no consensus on whether patients should have a legal right to a reassessment of their condition and prognosis and access to medical treatment and therapies. Instead, what materialized 
strongly was that capricious chance factors were often the deciding elements in whether or not a patient would be clinically reassessed. This is instead of clinical or medical indicators. Decision-making on reassessment was not routine and predictable. This outcome was not what we had expected to find. The ramifications of this finding for patient rights are significant—and point to the importance of having protocols adhered to uniformly in the care and treatment of all patients. It points out the vulnerability of patients who do not have family or friends to act as their advocate.

Based upon our experiences, we would certainly recommend the use of grounded theory for qualitative research projects and particularly for those that seek to bring new insights to a field of enquiry.

\section{Exercises and Discussion Questions}

1. When might focus groups be considered a method of choice for data collection?

2. What is a pilot study and what are the potential benefits?

3. What practicalities need to be considered at the design stage of focus group research?

4. Why use a grounded theory approach for data analysis?

5. What considerations should be given in the construction of an approach to axial coding, given the divergent views on this within grounded theory methodology?

6. How would you go about constructing a narrative in the third coding stage of grounded theory?

\section{Further Reading}


Charmaz, K. (2014). Constructing grounded theory: A practical guide through qualitative analysis. London, England: SAGE.

Flick, U. (2014). The SAGE handbook of qualitative data analysis. London, England: SAGE.

Harry, B., Sturges, K., \& Klinger, J. (2005). Mapping the process: An exemplar of process and challenge in grounded theory analysis. Educational Researcher, 34(2), 3-13.

Kitzinger, J. (1995). Introducing focus groups. British Medical Journal, 311, 299-302.

Morgan, D. L. (1996). Focus groups. Annual Review of Sociology, 22, 129-152.

Stewart, D. W., \& Shamdasni, P. N. (2015). Focus groups: Theory and practice (3rd ed.). London, England: SAGE.

\section{Web Resources}

National Centre for research methods: http://eprints.ncrm.ac.uk/

Five short videos from a lecture on Grounded Theory:

http://onlineqda.hud.ac.uk/movies/Grounded_Theory/index.php Social Research Update: http://sru.soc.surrey.ac.uk/SRU19.html

\section{References}


Charmaz, K. (2006). Constructing grounded theory: A practical guide through qualitative analysis. London, England: SAGE.

Connelly, L. M. (2015). Focus groups: Research roundtable. Medsurg Nursing, 24, 369370.

Duggleby, W. (2005). What about focus group interaction data? Qualitative Health Research, 15, 832-840.

Krueger, R. A., \& Casey, M. A. (2008). Focus groups: A practical guide for applied research. Los Angeles, CA: SAGE.

Sargent, S. (2009). The best interests of the child in intercountry adoption: A constructivist and comparative account (Unpublished $\mathrm{PhD}$ thesis). Retrieved from https://www.dora.dmu.ac.uk/bitstream/handle/2086/3535/Sargent,\%20Sarah\%20PhD .pdf?sequence $=1$

Strauss, A., \& Corbin, J. (1998). Basics of qualitative research: Techniques and procedures for developing grounded theory. London, England: SAGE.

Wilson Scott, K. (2004). Relating the categories in grounded theory analysis: Using a conditional relationship guide and reflective coding matrix. The Qualitative Report, 9(1), 112-126. 